\title{
Viscous Dissipation and Heat Transfer Effect on MHD Boundary Layer flow past a Wedge of Nano fluid Embedded in a Porous media
}

\author{
${ }^{a}$ N. Amar and ${ }^{b}$ N. Kishan \\ ${ }^{\mathrm{a}, \mathrm{b}}$ Department of Mathematics, Osmania University Hyderabad, Telangana-50007.
}

Article History: Received: 11 January 2021; Accepted: 27 February 2021; Published online: 5 April 2021

\begin{abstract}
:
In this investigation the steady of laminar magnetohydrodynamic(MHD) heat and mass transfer two dimensional boundary layer nanofluid flow past a wedge embedded in a porous media in the availability of the viscous dissipation, thermophoresis and Brownian motion effects are taken into account. With the assistance of the similarity transformation, the governing partial differential equations (PDE) are transformed into nonlinear ordinary differential equations (ODE). The solution of the problem is solved numerically by using the MATLAB in built package solver bvp4c. The method's accuracy is examined against recently discussed results and outstanding agreement was reached. The impacts of the pertinent flow parameters are examined through graphs and tabular form.
\end{abstract}

\section{Introduction:}

For some applications of thermal engineering such as crude oil refinement, geothermal process, thermal isolation, heat exchangers and radioactive waste disposals, convective heat and mass movement of liquids are assured. The laminar model was first extracted in the work of Falkner and Skan [1]. Hartree [2] researched the equations of fluid dynamics arising in Falkner and Skan's estimated behaviour of the equations of fluid dynamics. as time went by, more researchers started to find a few in the broad popularity and utilisation of simple physical phenomenon of boundary layer motion past a wedge. Ali et al.[3] examined the on the moving wedge in a nanofluid by utilising the Buongiorno model the unsteady MHD solution of boundary layer flow and heat transfer. Beong In Yun[4] proposed an iterative process for the Falkner-Skan equation solution. Martin and Iain Boyd [5] analysed Falkner-Skan Flow over a wedge with slip boundary condition of the solutions are achieved by the finite difference method. The radiation impacts on the mixed convection flow of an optically thick viscous fluid over an isothermal wedge embedded in the porous non-Darcy medium was numerically studied in the influence of a heat source /sink was deliberate by Al-Odat et.al [6]. In non-Darcy free convection flow a mixture of heat and mass transfer is examined along a permeable vertical cylinder embedded in a saturated porous media was studied by Hossain et.al.[7]. An unsteady flow from a viscous, incompressible fluid is examined past a stretching wedge influenced by the viscous dissipation, magnetic transverse field, and wall slide was inspected by Nagendramma et.al.[8] and some of the researchers are studied in different aspects viz., Kandasamy [9] studied on thermal stratification due to solar energy radiation, Anjali devi[10] and Yih[11] investigated studied the effects of suction/injection effect, Alam et.al[12]considered the on micropolar fluid along with the porous wedge, Rahman[13] analysed heat and mass transfer effect, Kandasamy et.al.[14] discussed the NonDarcy over a Porous wedge.

The analysis of electric conducting fluids with magnetic properties that have an effect on the fluid flow characteristics is Magnetohydrodynamic(MHD). As events arise in a conducting fluid, a magnetic field causes a current. This influence polarises the fluid and thus affects the magnetic field (Makanda et al.[15]). Since MHD is used widely in scientific procedures such as plasma experiments, power generator designs and petroleum, for MHD, design for nuclear researchers' cooling heat sharing, and several other systems. There are many researchers worked on that the work of Kasmani et.al.[16] analyzed the generation/absorption and chemical reaction and suction effect on convective boundary layer fluid nanofluid flow through a Wedge. Alam et.al.[17] investigation on MHD fluid flow of heat transfer effect with moving Wedge in nanofluid. Non-Newtonian mixed convection power law fluid with different effects on a stretching sheet was investigated by Shakhaoath et.al.[18]. ImranUllah et.al.[19] examined Casson fluid hydromagnetic Falkner-Skan flux past a passing heat transfer wedge. Nanofluid plays an essential part in optimising fluid heat transfer properties. Enhanced thermal fluid conductivity and heat transfer coefficient are essential dimensions of nanofluid. Sattar[20] studied the similarity transformation of 2-D hydrodynamic boundary layer equations of the past wedge, Rahman[21] studied Rarefied fluid convective slip movement over a wedge with a thermal jump and variable transport properties. The influence of viscous dissipation affects the temperature profiles by performing a function as an energy source, resulting in a heat transfer rate and thus a heat transfer problem to be taken into account. Several recent research has been carried out to examine the MHD boundary layers in porous media in the presence and absence of viscous dissipation. Majesty and Gangadhar [22] investigate the viscous dissipation and radiation effect on MHD Nanofluid flow past a Wedge through porous medium. Rashid Ahmad Waqar and Ahmed Khan[23] investigate the viscous dissipation and internal heat generation on moving wedge with convective boundary conditions. Many researchers are studied the behavior of MHD flow of fluid over a various surface has been considered in different literatures viz.,[24-37] . 
The objective of this investigation deals with different impacts of the heat and mass transfer flow of MHD boundary layer flow past a wedge over a porous medium. The governing equations are changed into nonlinear ODEs by employing the similarity transformation and the numerical results are obtained by MATLAB inbuilt solver bvp4c. the impacts of the several non-dimensional constraints on velocity, temperature and concentration profile are investigated and explained through the graphs and tabular form.

\section{Mathematical Formulation:}

Consider the 2- Dimensional MHD boundary layer flow electrically conducting nanofluid past a wedge with heat and mass transfer through porous medium in the existence of the viscous dissipation impact. In this $x-$ axis is assumed parallel to the plate in the flow path and the $y-$ axis is towards the free stream as displayed in figure. The wall of the wedge is kept fixed temperature $\left(T_{w}\right)$ and nanoparticle concentration $\left(C_{w}\right)$, respectively, are larger than the ambient temperature $\left(T_{\infty}\right)$ and ambient nanoparticles $\left(C_{\infty}\right)$, respectively. The fluid has a continuous physical features and also supposed that constant magnetics $B_{0}$ is used in the positive y-axis and perpendicular to wedge wall. When compare with the employed magnetic field the induced magnetics field is very small so it is neglected (Ullah et al. [38]). With the above postulation the governing equations of the existing flow are as

Continuity:

$$
\frac{\partial u}{\partial x}+\frac{\partial u}{\partial y}=0
$$

Momentum equation: $u \frac{\partial u}{\partial x}+v \frac{\partial u}{\partial y}=-\frac{1}{\rho_{f}} \frac{\partial p}{\partial x}+v_{f} \frac{\partial^{2} u}{\partial y^{2}}-\left(\frac{\sigma B_{0}^{2}}{\rho_{f}}+\frac{V_{f}}{K}\right)$

Energy: $u \frac{\partial T}{\partial x}+v \frac{\partial T}{\partial y}=\alpha_{f} \frac{\partial^{2} T}{\partial y^{2}}+\frac{V_{f}}{c_{p}}\left(\frac{\partial u}{\partial y}\right)^{2}+\tau\left\{D_{B}\left(\frac{\partial T}{\partial y} \frac{\partial c}{\partial y}\right)+\frac{D_{T}}{T_{\infty}}\left(\frac{\partial T}{\partial y}\right)^{2}\right\}$

Nanoparticle concentration equation: $u \frac{\partial c}{\partial x}+v \frac{\partial C}{\partial y}=D_{B} \frac{\partial^{2} C}{\partial y^{2}}+\frac{D_{T}}{T_{m}} \frac{\partial^{2} T}{\partial y^{2}}$

The boundary conditions are given as

$$
\left.\begin{array}{lr}
u=0, v=0, T=T_{w}, C=C_{w} & \text { at } y=0 \\
u=U(x)=U_{\infty} x^{m}, T \rightarrow T_{\infty}, C \rightarrow C_{\infty} & \text { as } y \rightarrow \infty \\
u=U_{\infty}, T=T_{\infty} & \text { at } x=0
\end{array}\right\}
$$

Where $(u, v)$ are the velocity component along the $(x, y)$ direction, and the momentum equation gives that the pressure in the boundary layer is equal to the free stream for the any given $x$ coordinate. Since there is no vorticity needed. In this high number of Reynolds, basic Bernoulli's equation can be implemented. It is supposed that is the velocity of the fluid $U(x)=U_{\infty} x^{m}$ at wedge outside the boundary layer. The Eqn.(3) goes (Falkner \& Skan [1], and Nageeb et al. [38]).

$\frac{1}{\rho_{f}} \frac{\partial p}{\partial x}=U \frac{\partial U}{\partial x}+\left(\frac{\sigma B_{0}{ }^{2}}{\rho_{f}}+\frac{V_{f}}{K}\right) U$

By substituting the Eqn.(6) in (2)

$$
u \frac{\partial u}{\partial x}+v \frac{\partial u}{\partial y}=U \frac{\partial U}{\partial x}+V_{f} \frac{\partial^{2} u}{\partial y^{2}}+\left(\frac{\sigma B_{0}^{2}}{\rho_{f}}+\frac{V_{f}}{K}\right)(U-u)
$$

Here, $x$ is assessed from the tip of the wedge, $m$ is the arbitrary fixed value and is associated to the wedge angle which is called as the Falkner-Skan power-law constraint, \& $\beta=2 m /(1+m)_{\text {is }}$ the gradient of the Hartree pressure factor representing to $\beta=\frac{\Omega}{\pi}$ for the complete angle $\Omega$ of the wedge (Fig.1,[42]) 


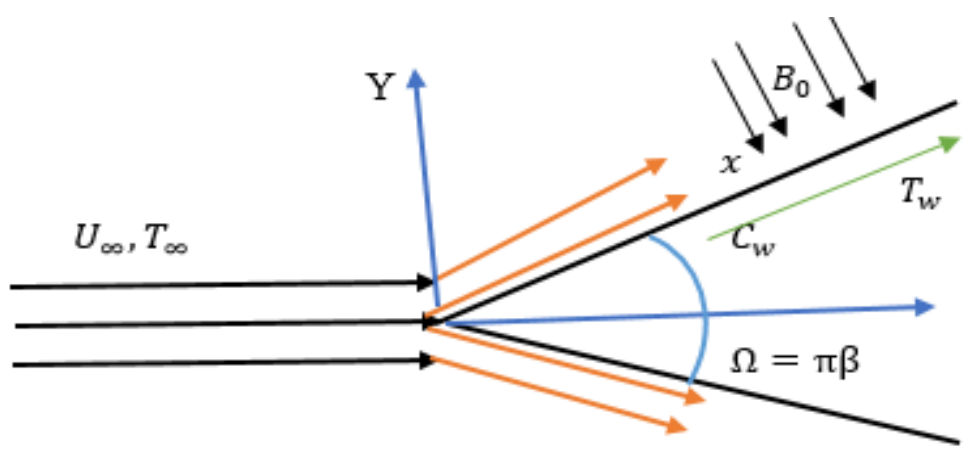

Fig.1.Geometry of the problem

Here the physical significance of the ${ }^{m}$ values follow as:

(i) If $m<0$ denotes that the adverse pressure gradient.

(ii) If $m>0$ denote the pressure gradient(Nagendramma et al. [8]).

(iii) If $m=0$ for Blasius solution which is equivalent to matching to an angle of occurrence of zero radians.

(iv) If $m=1$ corresponding to stagnation point flow.

Now introduce the stream function $\psi(x, y)$ such that $u=\frac{\partial \psi}{\partial y}, v=-\frac{\partial \psi}{\partial x}$ and the following similarity transformation ([22]\& [32]):

$$
\begin{aligned}
& \xi=y\left(\frac{(1+m) U_{\infty}}{2 V_{f}}\right)^{\frac{1}{2}} x^{\frac{(m-1)}{a}}, \psi\left(x, \eta=\left(\frac{2 V_{f} U_{\infty}}{1+m}\right)^{\frac{1}{2}} x^{\frac{(m+1)}{a}} f(\xi) f^{\prime}(\xi)=\frac{u}{v},\right. \\
& \theta(\xi)=\frac{T-T_{\infty}}{T_{w}-T_{m}}, \quad \phi(\xi)=\frac{c-c_{\infty}}{c_{w}-c_{m}} .
\end{aligned}
$$

By substituting the above transformations the Eq.(1) satisfied identically, and the Eq.(2-4) and (7) reduced to the subsequent set of ordinary differential Eqn. as

$$
\begin{aligned}
& f^{u v}+f f^{u}+\beta\left(1-f^{\prime 2}\right)+\frac{1}{1+m}(M+K)\left[1-f^{\prime}\right]=0 \\
& \theta^{n}+\operatorname{Pr}\left[f \theta^{\prime}+E c f^{n 2}+N b \theta^{\prime} \phi^{y}+N t \theta^{\prime 2}\right]=0 \\
& \phi^{n}+\operatorname{LePr}\left(f \phi^{y}\right)+\frac{N t}{N b_{b}} \theta^{v y}=0
\end{aligned}
$$

The changed boundary conditions are

$$
\begin{aligned}
& f=0, f^{\prime}=0, \theta=1, \phi=1 \text {, } \\
& f^{\prime} \rightarrow 1, \theta \rightarrow 0, \phi \rightarrow 0 \text {, } \\
& \left.\begin{array}{r}
\text { at } \xi=0 \\
\text { as } \xi \rightarrow \infty
\end{array}\right\} \\
& \text { Here } M=\frac{2 \sigma B_{0}{ }^{2} x^{1-m}}{\rho_{f} U_{\infty}}, K=\frac{2 V_{f} x^{1-m}}{K U_{\infty}}, E c=\frac{U^{2}}{c_{p}\left(T_{w}-T_{\infty}\right)}, P r=\frac{V_{f}}{\alpha_{f}}, L e=\frac{\alpha_{f}}{D_{B}}, \\
& N b=\frac{\tau D_{B}\left(C_{w}-C_{\infty}\right)}{V_{f}}, N t=\frac{\tau D_{\tau}\left(T_{w}-T_{\infty}\right)}{V_{f} T_{\infty}}, R e_{x}=\frac{U w_{x}}{V_{f}}
\end{aligned}
$$

The physical magnitudes of engineering importance in the this analysis are the skin friction coefficient $C_{f}$, local Nusselt number $N u_{x}$, and local Sherwood number $S h_{x}$, correspondingly, and specified as

$C_{f}=\frac{2 \tau_{w}}{\rho U^{2}(x)}, N u_{x}=\frac{x q_{w}}{K\left(T_{w}-T_{\infty}\right)}, S h_{x}=\frac{x M_{w}}{D_{R}\left(C_{w}-C_{\infty}\right)}$

the surface shear stress, heat flux, and mass flux, respectively, they are specified as

$$
\tau_{w}=\mu_{f}\left(\frac{\partial u}{\partial y}\right)_{y=0}, q_{w}=-K_{f}\left(\frac{\partial T}{\partial y}\right)_{y=0}, M_{w}=-D_{B}\left(\frac{\partial C}{\partial y}\right)_{y=0}
$$

The non-dimensional the rate velocity, the rate of temperature, and concentration are defined as

$$
C_{f}\left(R e_{x}\right)^{\frac{1}{2}}=2\left(\frac{m+1}{2}\right)^{\frac{1}{2}} f^{n}(0)
$$




$$
\begin{aligned}
& \frac{N u_{x}}{\left(R e_{x}\right)^{\frac{1}{2}}}=-\left(\frac{m+1}{2}\right)^{\frac{1}{2}} \theta^{\prime}(0) \\
& \frac{S h_{x}}{\left(R e_{x}\right)^{\frac{1}{2}}}=-\left(\frac{m+1}{2}\right)^{\frac{1}{2}} \phi^{\prime}(0)
\end{aligned}
$$

\section{Results and Discussion:}

The solution of the governing PDEs is reduced in the nonlinear ODEs by employing the similarity transformations. Calculations have been carried out by the MATLAB inbuilt solver for changed values of the non-dimensional parameters.

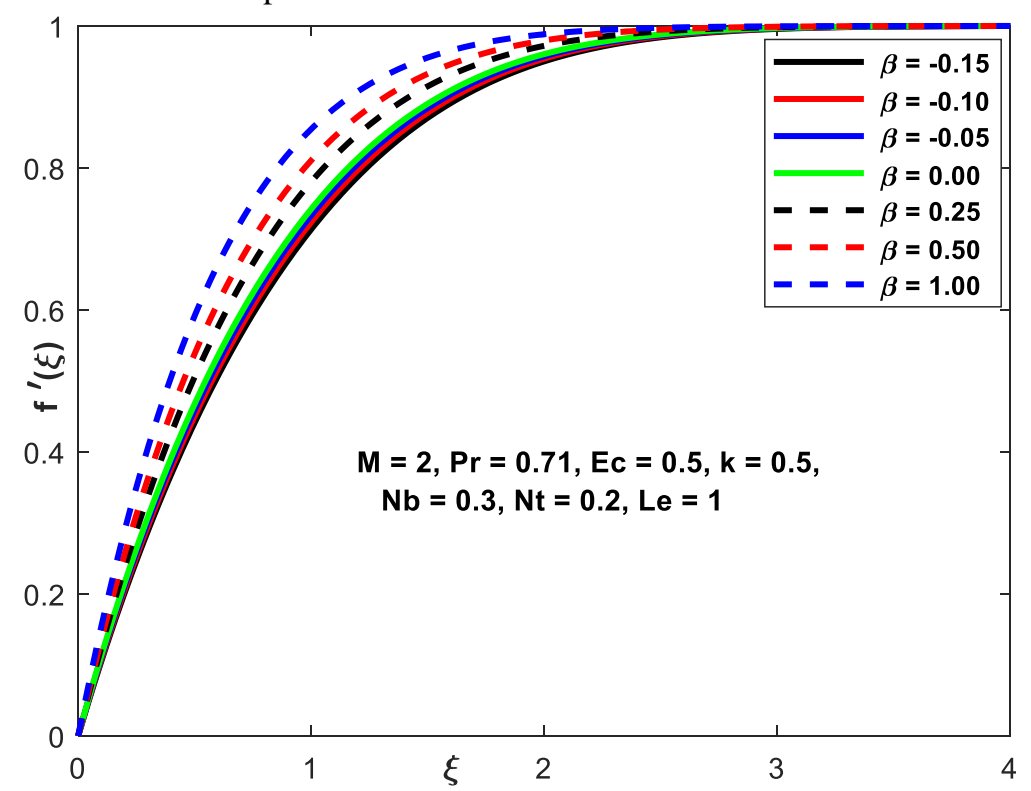

Fig. 2. Velocity v/s Pressure Gradient.

Fig. 2 indicates that the velocity profile variation for various pressure gradient factor values $\beta$. It is obviously, shows that the velocity curves enhance with a rise the parameter of pressure gradient. Due to the wedge angle increment, fluid moves even slower and diminishes the thickness of the velocity boundary.

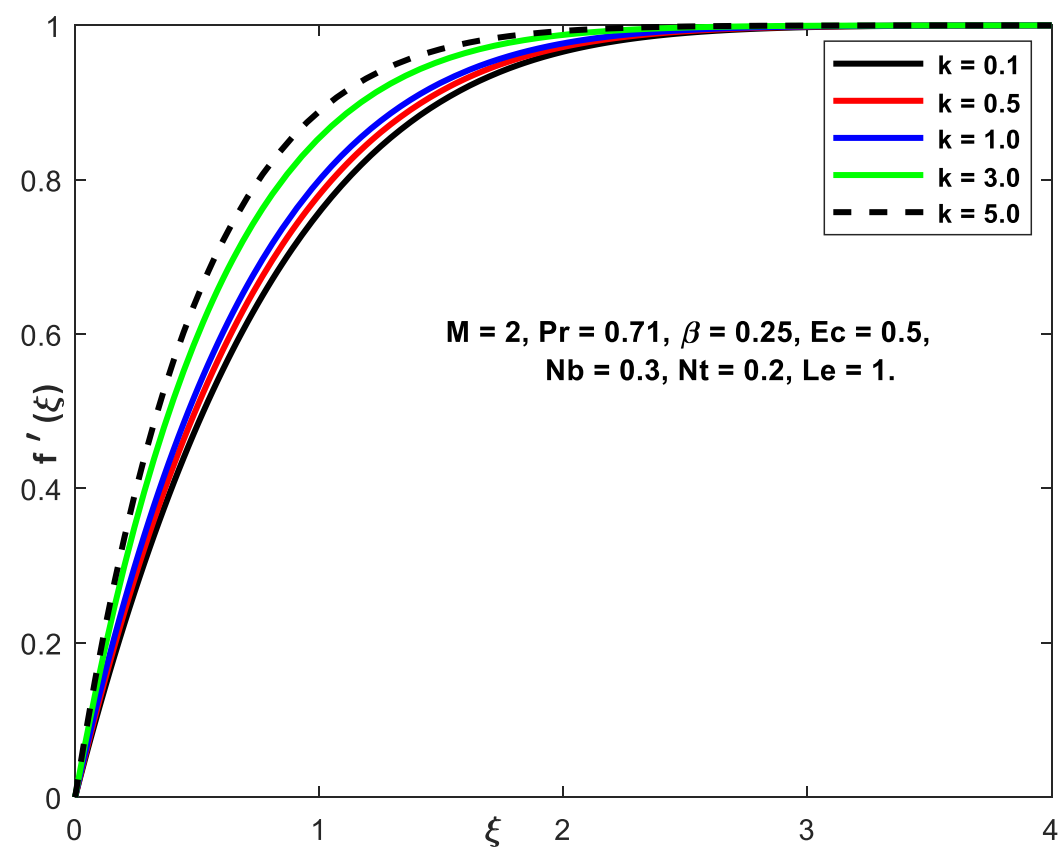

Fig. 3. Velocity v/s Permeability parameter.

The influence of the permeability parameter on velocity curves is shown in Fig.3. It is illustrious that the rise of $k$, the nanofluid velocity increases on porous surface and decrease the width of its boundary layer. 


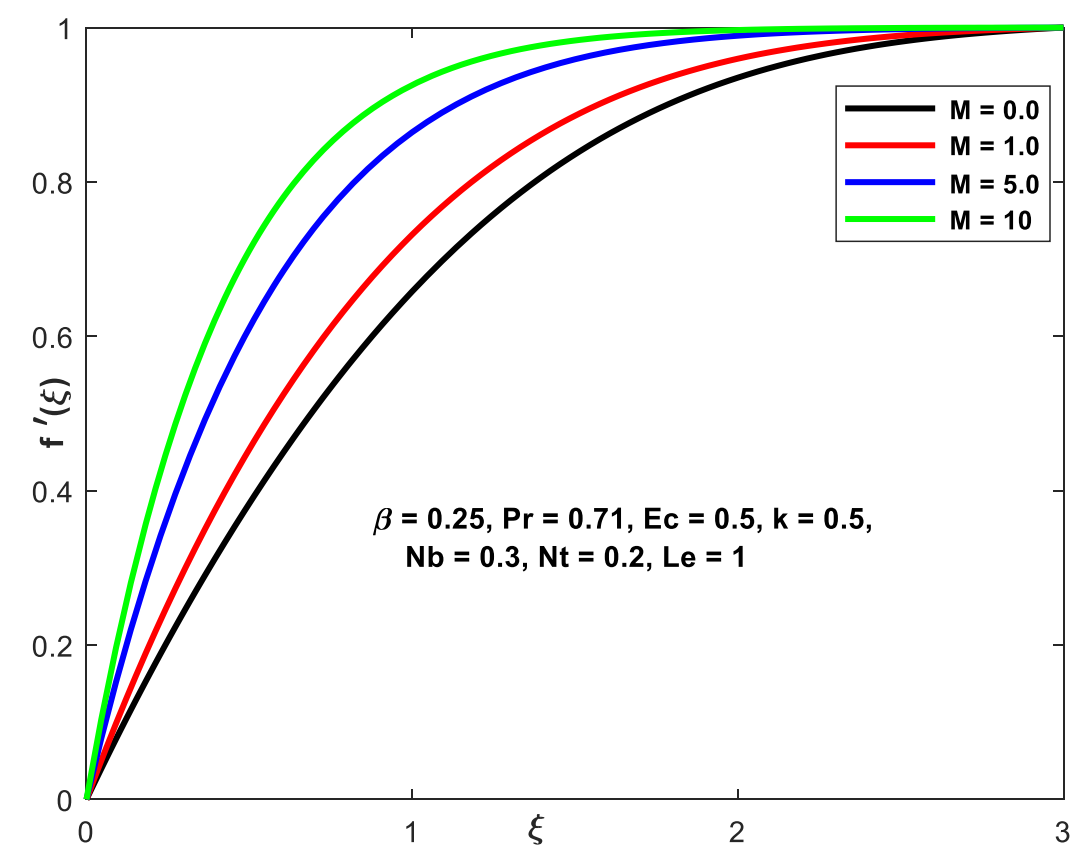

Fig.4. velocity v/s Magnetic parameter.

The difference of temperature with Magnetics parameter is diagrammed in Fig.4. It is obvious that the velocity rises with an increase of the magnetics parameter increases. This is because the presence of a magnetic transverse field is the Lorentz force which outcomes in a retarded force on the velocity profile.

Fig.5 illustrate that the influence of the Magnetic parameter on the velocity distribution. The figure indicates that temperature profiles declines with an enhance of Magnetics parameter values.

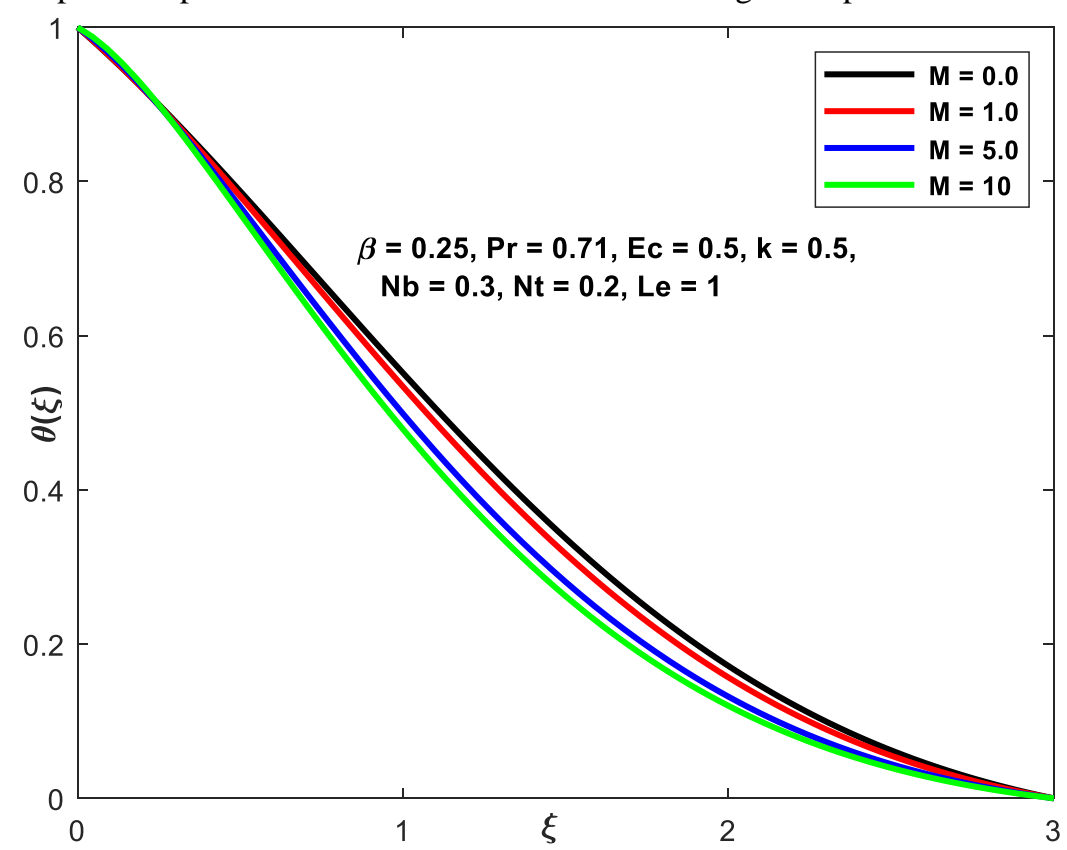

Fig.5. Temperature v/s Magnetic parameter. 


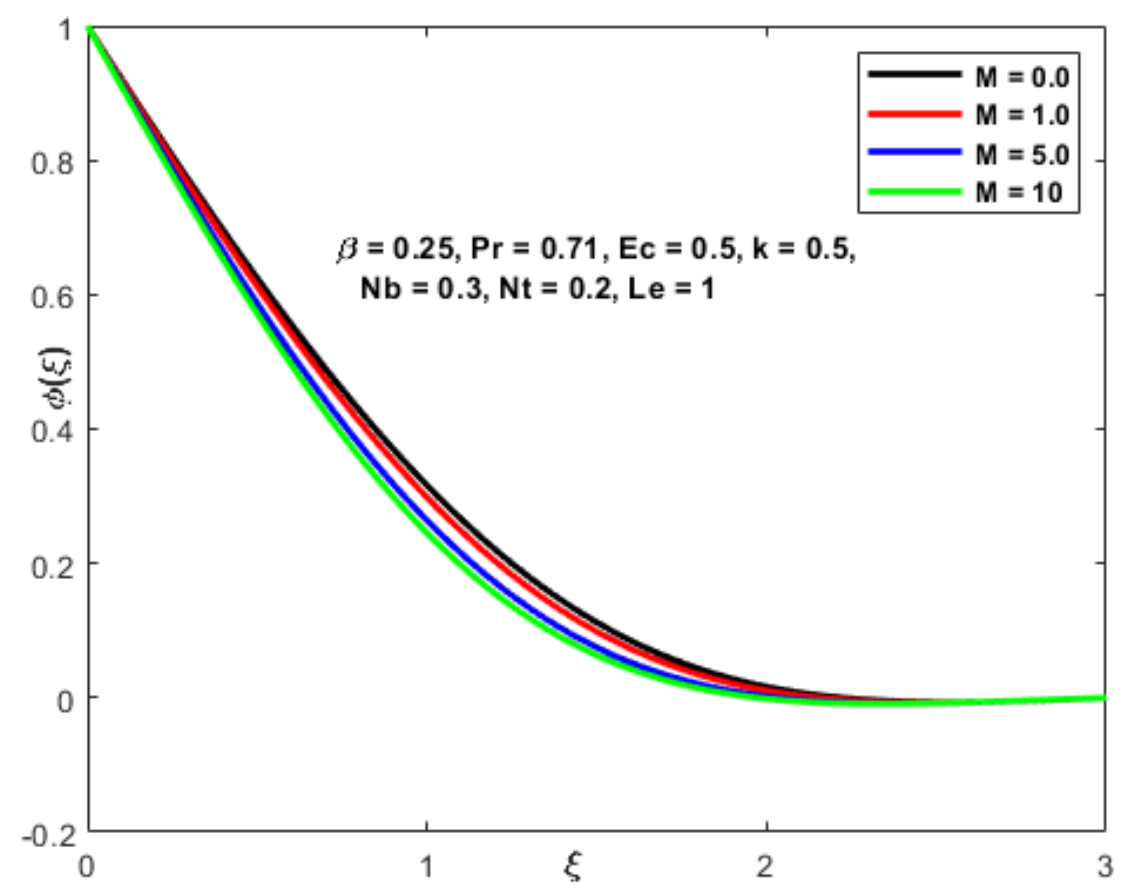

Fig.6. Concentration v/s Magnetic parameter.

Fig.6 display the impact of the magnetic parameter on the concentration distribution. As the values of the magnetic parameter raises the concentration curve decreases.

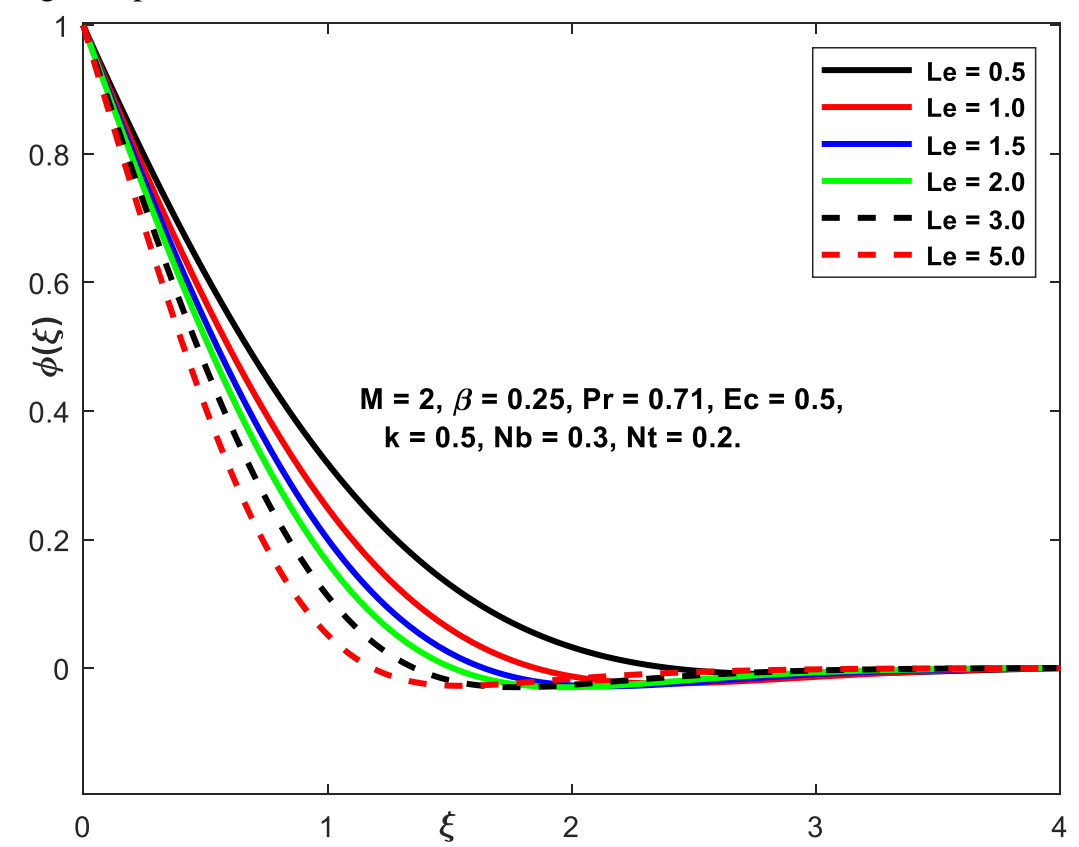

Fig.7. Concentration v/s Magnetic parameter.

Fig.7 displays the concentration distribution mechanism for numerous values of the Lewis number. The concentration profile falls further as the Lewis number rises, but even the boundary layer thickness declines. 


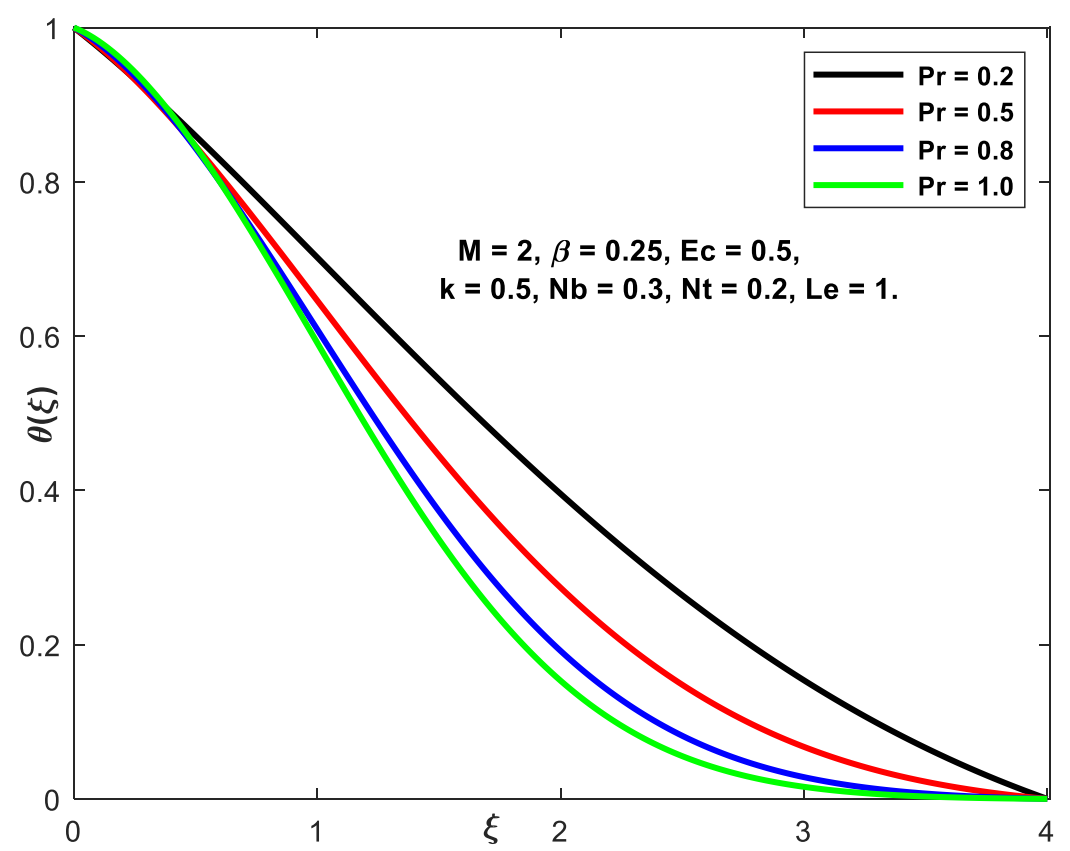

Fig.8. Temperature v/s Prandtl number.

The impact of the Prandtl number on the temperature curves is sketched in the Fig.8. Since enhancing Prandtl number appears to diminish the thermal diffusivity of the fluid and to induce a slow penetration of the heat within the fluid.

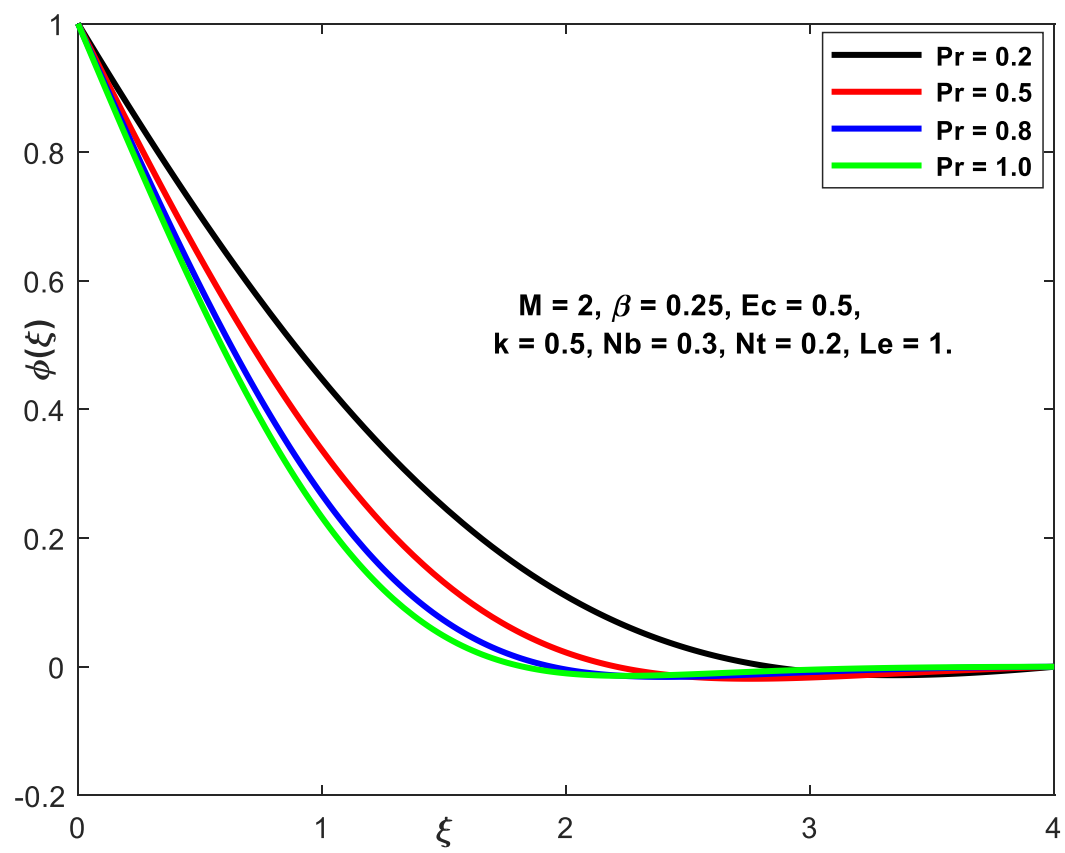

Fig.9. Concentration v/s Prandtl number.

The Prandtl number and its effect on the concentration curve is shown in Fig.9.This is noticed that then rise in the values of ${ }^{P r}$ decreases the fluid concentration inside the boundary layer. 


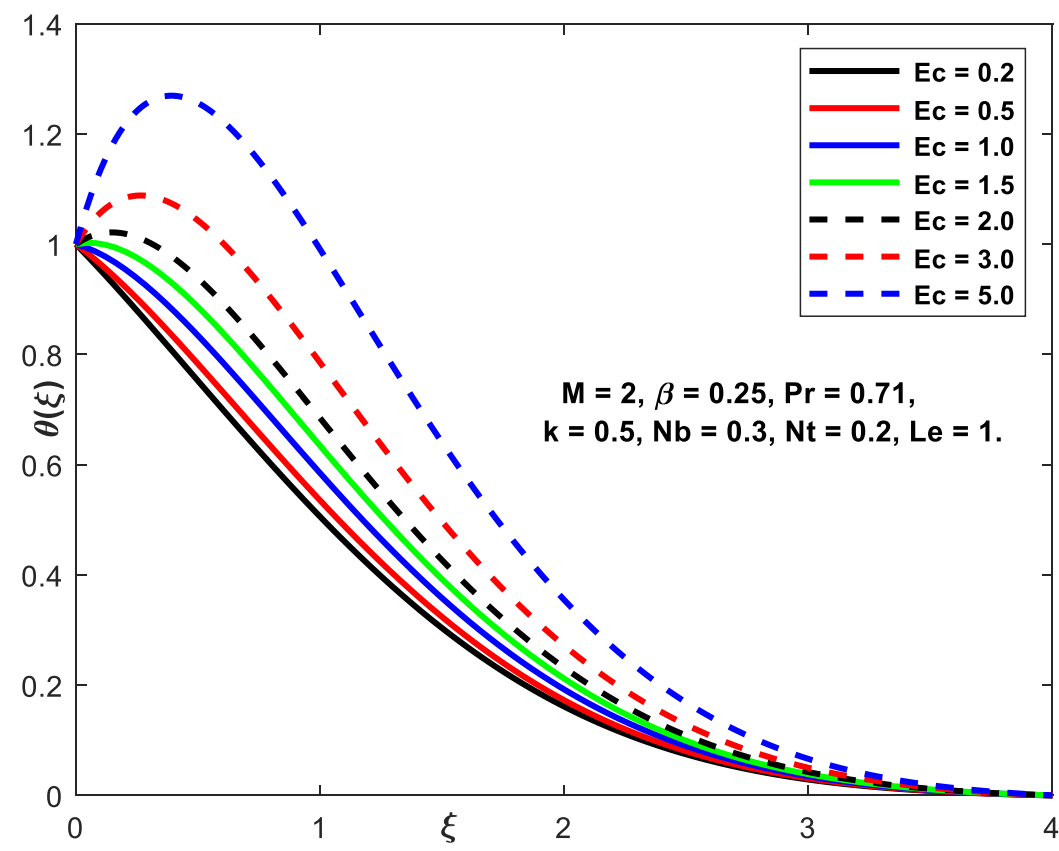

Fig.10. Temperature v/s Eckert number.

The influence of the Eckert number on the temperature curves is depicted in the Fig 10. The Eckert number represents the transformation of kinetic energy into internal energy by function versus viscous fluid tension. This is identified that the temperature rises with an enhance of the viscous dissipation parameter.

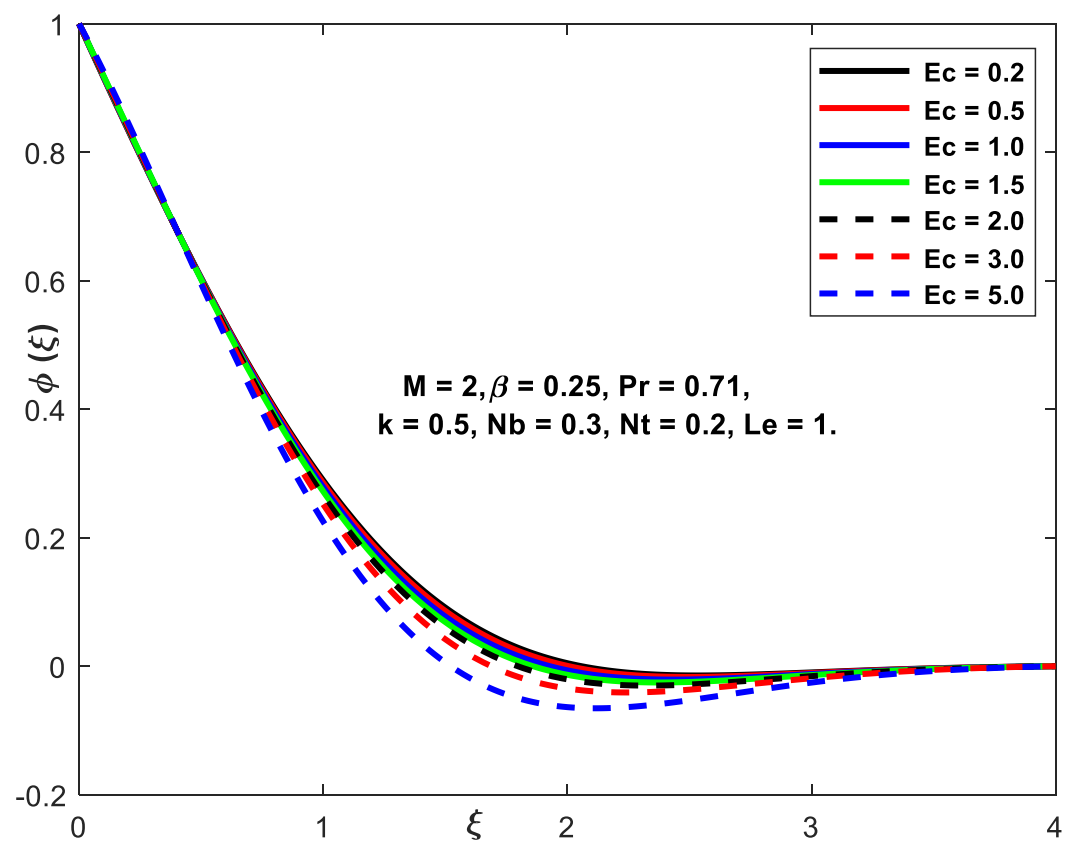

Fig.11. Concentration profile v/s Eckert number.

The outcome of Eckert number $(E c)$ on concentration curves is well marked in Fig.11. It is seen that an increase of $E c$ leads to decline gradually the concentration profile. 


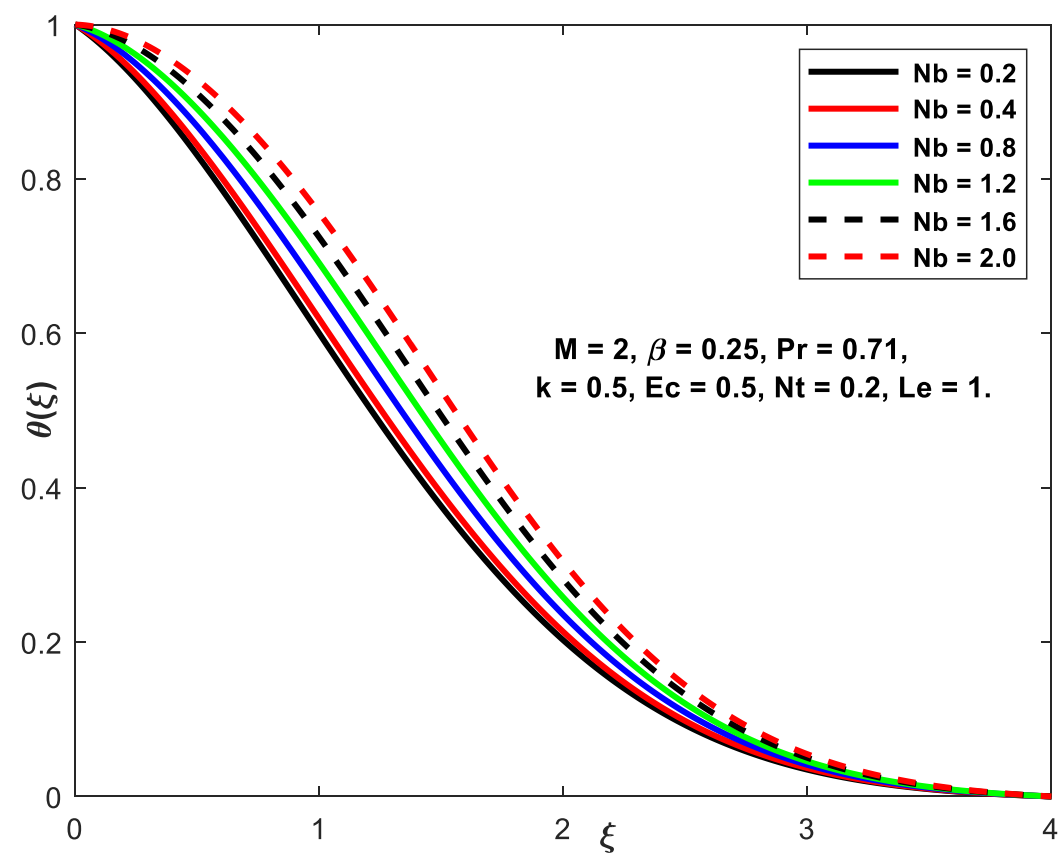

Fig.12. Temperature profile v/s Brownian motion parameter.

The effect of the Brown motion parameter $N b$ Nanofluid temperature profiles are seen in Fig. 12. It shows that the temperature curves rises with enhances in $N b_{v}$ especially in the near-surface area. As this occurs, the raised $\mathrm{Nb}$ actually raises the thickness of the thermal boundary sheet, which consequently increases the temperature.

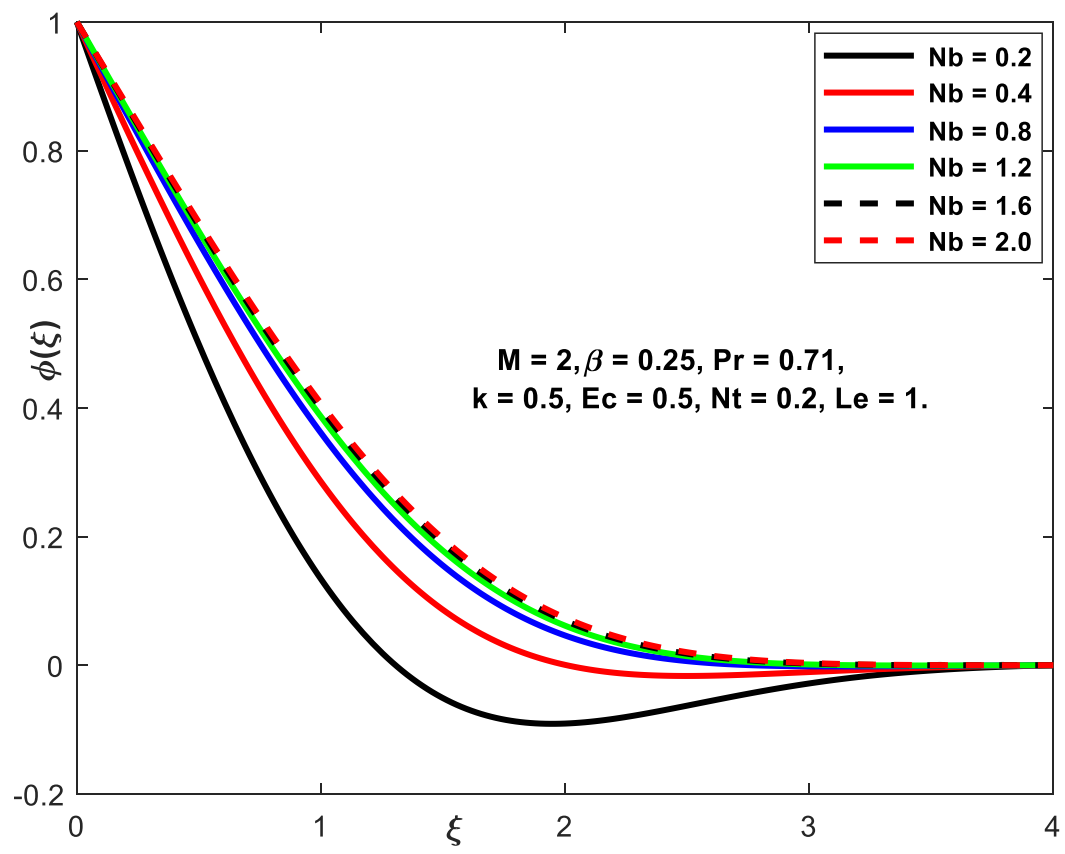

Fig.13. Concentration profile v/s Brownian motion parameter.

The impact of the Brownian motion parameter on the concentration curves are plotted in Fig.13. It illustrate that the rise in $N b$ values gradually decreases the relatively close concentration profile. 


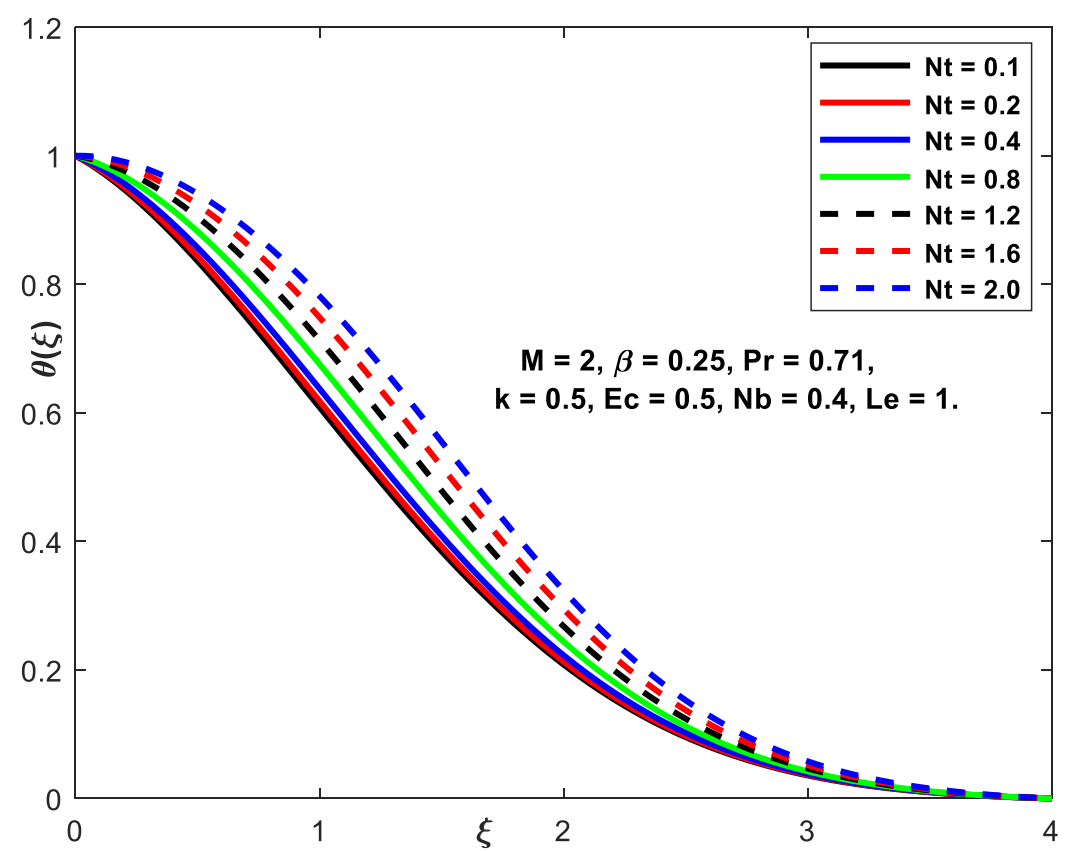

Fig.14. Temperature profile v/s thermophoresis parameter.

The fluctuation of temperature with thermophoresis parameter is illustrate in Fig.14. The thermophoresis force that occurs from the temperature gradient allows the fluid to move more rapidly, and thus the fluid is heated further. As a consequence, the greater the value of $N t$ rise the temperature curves and the thickness of its boundary layer a s seen in figure.

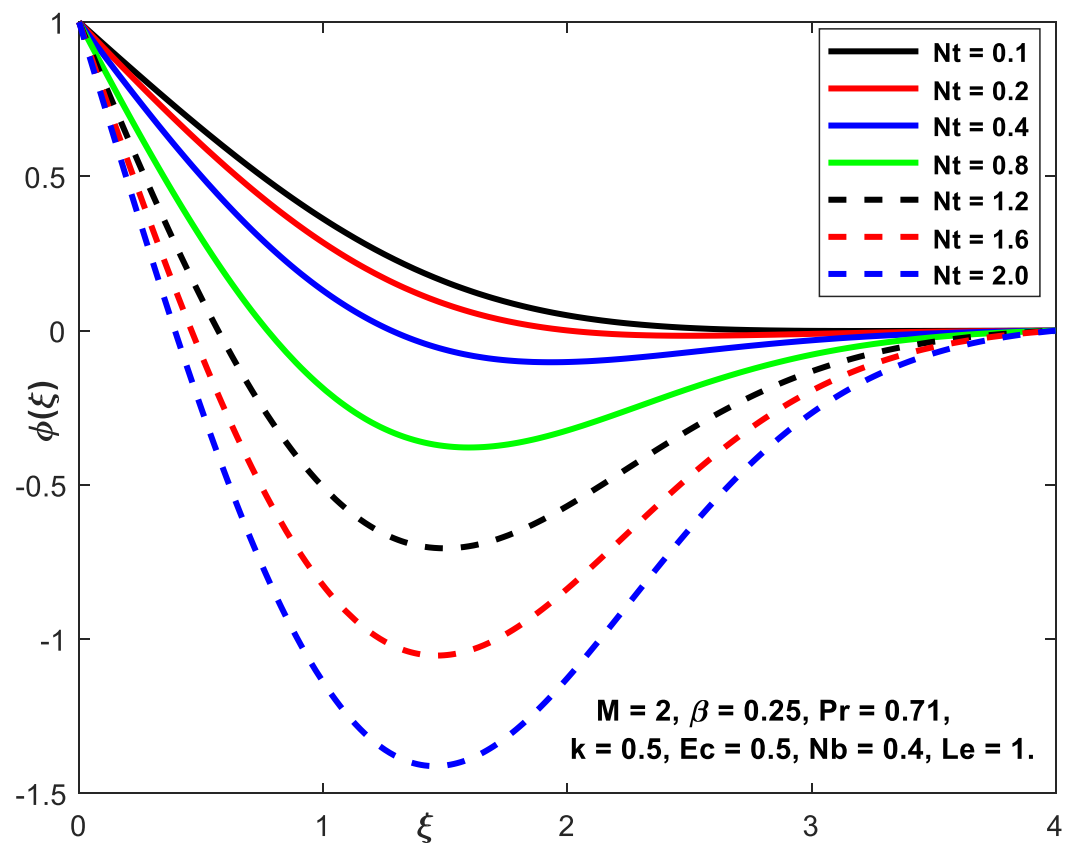

Fig.15. Concentration profile v/s thermophoresis parameter.

The behaviour in the concentration profiles for altered values of the thermophoresis parameter were displayed in Fig.15. It demonstrates conveniently that the concentration inside the boundary layer diminution with the rising Nt values.

It has been observed in the Table 1 that there is a good agreement among the result given by bvp4c code and those mentioned by [20], [21], [22] and [23] we are also very sure that the latest outcomes are correct. Table 2 describes the effect of the dimensionless constraints on the skin friction quantity, local Nusselt and local Sherwood numbers. The skin friction quantity increases with a rise of pressure gradient magnetic parameter, and, permeability parameter. with an enhance of pressure gradient, Prandtle number, thermophoresis constraint, Lewis number, magnetics parameter, the local Nusselt number decreases and local Sherwood number increases.

\section{CONCLUSIONS}


In this work, the impacts of the viscous dissipation, thermophoresis, Brownian motion on MHD fluid boundary layer flow past a wedge with heat and mass transfer of Nanofluid embedded in porous media has been studied. By utilizing the appropriate similarity transformations, the PDEs are changed to a set of nonlinear ODEs and solutions are obtained by MATLAB software package such as bvp4c tool. From the present numerical discuss, the flowing observations found and given below:

- With an increase of $\beta, K$ and $M$ the velocity declines.

- Temperature increases with an enhance of $E c, N b$ and $N t$.

- Concentration profile declines with an increase of $P r, L e, N b$ and M.

- With an increase of $\beta, K$, and $M_{v}$ leads to enhance in skin-friction quantity .

- With an increase of $\beta, M K N t$ and $E c$ the result in local Nusselt number is a decreases, but the reverse effect is found in local Sherwood number .

Table 1: Variations of the bvp4c results of $f^{\prime \prime}(0), \quad-\theta^{\prime}(0)$ for different values of $m$ for $k=M=E c=N t=L e=0, P r=0.73$, and $N b=10^{-5}$,

\begin{tabular}{|c|c|c|c|c|c|c|c|c|}
\hline \multirow[b]{2}{*}{$\mathrm{m}$} & \multicolumn{5}{|l|}{$-f^{s y}(0)$} & \multicolumn{3}{|l|}{$-\theta^{y}(0)$} \\
\hline & $\begin{array}{l}\text { Ashwini[3 } \\
\text { 9] }\end{array}$ & $\frac{\text { Watanaba }}{0]}[4$ & $\frac{\text { Ullah }}{\text { [41] }}$ & $\begin{array}{l}\text { Ibrahim } \\
\& \\
\text { Tulu[42 } \\
\text { ] }\end{array}$ & $\begin{array}{l}\text { Presen } \\
\mathrm{t}\end{array}$ & $\begin{array}{l}\text { Watanaba[4 } \\
0]\end{array}$ & $\begin{array}{l}\text { Ibrahim } \\
\& \\
\text { Tulu[42 } \\
\text { ] }\end{array}$ & Present \\
\hline 0 & 0.4696 & 0.4696 & $\begin{array}{l}0.469 \\
6 \\
\end{array}$ & 0.4696 & $\begin{array}{l}0.469 \\
6 \\
\end{array}$ & 0.42015 & 0.42016 & $\begin{array}{l}0.4201 \\
2\end{array}$ \\
\hline $\begin{array}{l}0.014 \\
1\end{array}$ & 0.5046 & 0.50461 & $\begin{array}{l}0.504 \\
6\end{array}$ & 0.50461 & $\begin{array}{l}0.504 \\
6\end{array}$ & 0.42578 & 0.42578 & 0.4258 \\
\hline $\begin{array}{l}0.043 \\
5\end{array}$ & 0.569 & 0.56898 & 0.569 & 0.56898 & $\begin{array}{l}0.568 \\
9\end{array}$ & 0.43548 & 0.43548 & 0.4355 \\
\hline $\begin{array}{l}0.090 \\
9\end{array}$ & 0.655 & 0.65498 & 0.655 & 0.65498 & $\begin{array}{l}0.654 \\
9\end{array}$ & 0.4473 & 0.44730 & 0.4473 \\
\hline $\begin{array}{l}0.142 \\
9\end{array}$ & 0.732 & 0.732 & 0.732 & 0.732 & 0.732 & 0.45693 & 0.45694 & 0.4569 \\
\hline 0.2 & 0.8021 & 0.80213 & $\begin{array}{l}0.802 \\
1\end{array}$ & 0.80213 & $\begin{array}{l}0.802 \\
1\end{array}$ & 0.46503 & 0.46503 & 0.4650 \\
\hline $\begin{array}{l}0.333 \\
3\end{array}$ & 0.9277 & 0.92765 & $\begin{array}{l}0.927 \\
7\end{array}$ & 0.92765 & $\begin{array}{l}0.927 \\
6\end{array}$ & 0.47814 & 0.47814 & 0.4781 \\
\hline 1 & 1.2326 & & $\begin{array}{l}1.232 \\
6\end{array}$ & 1.23258 & $\begin{array}{l}1.232 \\
5\end{array}$ & & & \\
\hline
\end{tabular}

Table 2: Comparisons of $f^{\prime \prime}(0),-\theta^{\prime}(0)$ and $-\phi^{\prime}(0)$ for different parameters.

\begin{tabular}{|c|c|c|c|c|c|c|c|c|c|c|c|c|c|}
\hline & & & & & & & & \multicolumn{3}{|c|}{ Ibrahim \& Tulu[42] } & \multicolumn{3}{|c|}{ Present study } \\
\hline$\beta$ & $M$ & $\kappa$ & $\begin{array}{l}P \\
r\end{array}$ & $\begin{array}{l}E \\
c\end{array}$ & $\begin{array}{l}N \\
b\end{array}$ & $\begin{array}{l}N \\
t\end{array}$ & $\begin{array}{l}L \\
e\end{array}$ & $-f^{n}(0)$ & $-\theta^{y}(0)$ & $-\phi^{\prime}(0)$ & $f^{n}(0)$ & $-\theta^{y}(0)$ & $-\phi^{\prime}(0)$ \\
\hline $\begin{array}{l}0.2 \\
5\end{array}$ & 2 & $\begin{array}{l}0 . \\
5\end{array}$ & $\begin{array}{l}0 . \\
5\end{array}$ & $\begin{array}{l}0 . \\
5\end{array}$ & $\begin{array}{l}0 . \\
4\end{array}$ & $\begin{array}{l}0 . \\
2\end{array}$ & $\begin{array}{l}1 . \\
5\end{array}$ & $\begin{array}{l}1.642831 \\
84\end{array}$ & $\begin{array}{l}0.20409 \\
76\end{array}$ & $\begin{array}{l}0.56485 \\
05\end{array}$ & $\begin{array}{l}1.64 \\
28\end{array}$ & $\begin{array}{l}0.20 \\
41\end{array}$ & $\begin{array}{l}0.56 \\
49\end{array}$ \\
\hline 0.5 & & & & & & & & $\begin{array}{l}1.649256 \\
59\end{array}$ & $\begin{array}{l}0.20245 \\
35 \\
\end{array}$ & $\begin{array}{l}0.56792 \\
27 \\
\end{array}$ & $\begin{array}{l}1.64 \\
93 \\
\end{array}$ & $\begin{array}{l}0.20 \\
25 \\
\end{array}$ & $\begin{array}{l}0.56 \\
79 \\
\end{array}$ \\
\hline 1.0 & & & & & & & & $\begin{array}{l}1.662020 \\
20\end{array}$ & $\begin{array}{l}0.19918 \\
04\end{array}$ & $\begin{array}{l}0.57392 \\
55\end{array}$ & $\begin{array}{l}1.66 \\
20\end{array}$ & $\begin{array}{l}0.19 \\
92\end{array}$ & $\begin{array}{l}0.57 \\
39 \\
\end{array}$ \\
\hline $\begin{array}{l}0.2 \\
5\end{array}$ & 1 & & & & & & & $\begin{array}{l}1.352138 \\
17\end{array}$ & $\begin{array}{l}0.22650 \\
83\end{array}$ & $\begin{array}{l}0.52246 \\
83\end{array}$ & $\begin{array}{l}1.35 \\
21\end{array}$ & $\begin{array}{l}0.22 \\
65\end{array}$ & $\begin{array}{l}0.52 \\
25\end{array}$ \\
\hline & 3 & & & & & & & $\begin{array}{l}1.889814 \\
23\end{array}$ & $\begin{array}{l}0.18295 \\
13\end{array}$ & $\begin{array}{l}0.60015 \\
61\end{array}$ & $\begin{array}{l}1.88 \\
98\end{array}$ & $\begin{array}{l}0.18 \\
30\end{array}$ & $\begin{array}{l}0.60 \\
02\end{array}$ \\
\hline & 5 & & & & & & & $\begin{array}{l}2.306223 \\
96\end{array}$ & $\begin{array}{l}0.14414 \\
67 \\
\end{array}$ & $\begin{array}{l}0.65848 \\
61 \\
\end{array}$ & $\begin{array}{l}2.30 \\
62 \\
\end{array}$ & $\begin{array}{l}0.14 \\
41 \\
\end{array}$ & $\begin{array}{l}0.65 \\
85 \\
\end{array}$ \\
\hline & 2 & $\begin{array}{l}0 . \\
2\end{array}$ & & & & & & $\begin{array}{l}1.561229 \\
53\end{array}$ & $\begin{array}{l}0.21069 \\
26\end{array}$ & $\begin{array}{l}0.55304 \\
97\end{array}$ & $\begin{array}{l}1.56 \\
12 \\
\end{array}$ & $\begin{array}{l}0.21 \\
07\end{array}$ & $\begin{array}{l}0.55 \\
30 \\
\end{array}$ \\
\hline
\end{tabular}




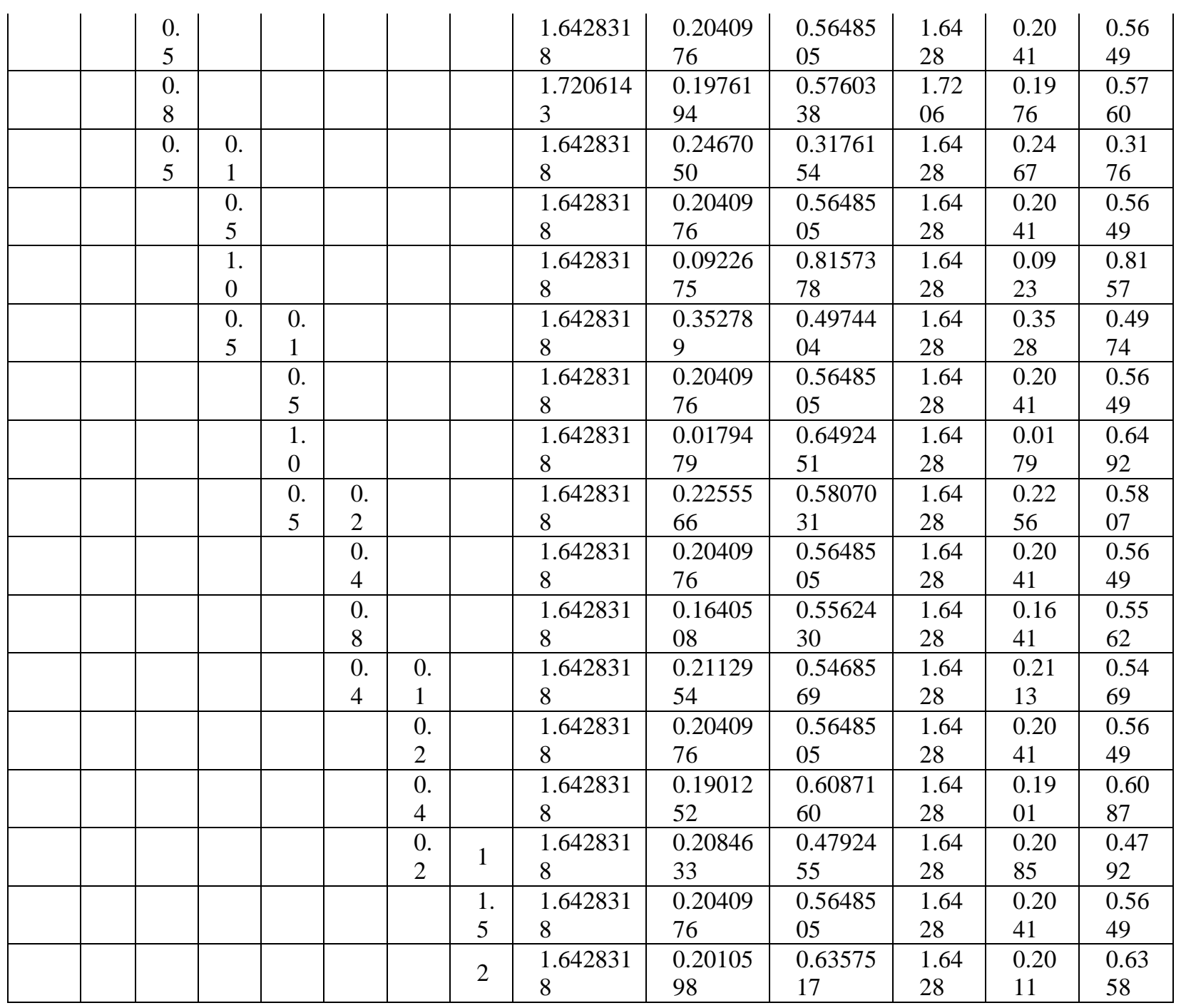

CONFLICT OF INTERESTS

The authors declare that there is no conflict of interests.

\section{REFERENCES:}

1. V. M. Falkner and S. W. Skan, "Some approximate solutions of the boundary layer equations," Philosophical Magazine, 12,1931, pp. 865-896.

2. D. R. Hartree, "On an equation occurring in Falkner and Skan's approximate treatment of the equations of the boundary layer,"Mathematical Proceedings of the Cambridge Philosophical Society, 33(2), 1937, pp. 223-239.

3. Ali M., Alim M. A., Nasrin R., Alam M. S., Haque Munshi M. J. Similarity Solution of Unsteady MHD Boundary Layer Flow and Heat Transfer past a Moving Wedge in a Nanofluid using the Buongiorno Model. Procedia Engineering. 194,2017, pp. 407- 413.

4. Beong In Yun "New Approximate Analytical Solutions of the Falkner-Skan Equation", Hindawi Publishing Corporation Journal of Applied Mathematics Volume 2012, Article ID 170802, 12 pages doi:10.1155/2012/170802.

5. Michael J. Martin and Iain D. Boyd "Falkner-Skan Flow over a wedge with slip boundary conditions", Journal of Thermophysics and Heat Transfer 24(2), 2010, pp.263-270. 
6. M.Q. Al-Odat - F.M.S. Al-Hussien - R.A. Damseh Influence of radiation on mixed convection over a wedge in non-Darcy porous medium, Forsch Ingenieurwes, 69, 2005, pp.209-215. DOI 10.1007/s10010-005-0004-2.

7. M.A.Hossain, KambizVafai, Khalil M.N.Khanafer "“ Non-Darcy natural convection heat and mass transfer along a vertical permeable cylinder embedded in a porous medium”, Int.Journal of Thermal Sci. ,38(10),1999, pp.854-862. https://doi.org/10.1016/S1290-0729(99)80040-4.

8. Nagendramma V, Sreelakshmi K, Sarojamma G "MHD heat and mass transfer flow over a stretching wedge with convective boundary condition and thermophoresis, Procedia Eng.127, 2015, pp. 963-969. https://doi.org/10.1016/j.proeng.2015.11.444.

9. R. Kandasamy, I. Muhaimin, A. B. Khamis, and R. B. Roslan, "Unsteady Hiemenz flow of $\mathrm{Cu}$-nanofluid over a porous wedge in the presence of thermal stratification due to solar energy radiation: Lie group transformation," Int.1 Journal of thermal Sciences, 65, 2013 pp. 196-205.

10. Anjali Devi, R. Kandasamy, Effects of heat and mass transfer on MHD laminar boundary layer flow over a wedge with suction or injection, J. Energy Heat Mass Transf. 23, pp.167-178, 2001.

11. K. A. Yih, "Uniform suction/blowing effect on forced convection about a wedge: uniform heat flux," Acta Mechanica, 128(3-4),1998, pp. 173-181. https://doi.org/10.1007/BF01251888.

12. Alam M. S., Tariku Islam and Rahman M. M. "Unsteady Hydromagnetic Forced Convective Heat Transfer Flow of a Micropolar Fluid Along a Porous Wedge With Convective Surface Boundary Condition", International Journal of Heat and Technology. 33(2), 2015, pp.115-122. DOI: https://doi.org/10.18280/ijht.330219.

13. Rahman ATM. M., Alam M. S., Chowdhury M. K. and Rahman M.M. Unsteady TwoDimensional Convective Heat and Mass Transfer Flow along a Wedge with Thermophoresis. International Conference on Mechanical Engineering. 2011,pp.1-7.

14. Kandasamy R., Muhaimin I. and Rosmila A.I. The performance evaluation of unsteady MHD NonDarcy flow over a porous wedge due to renewable (solar) energy. Renewable Energy. 64.,2014, pp.1-9.

15. G. Makanda, Numerical study of convective fluid flow in porous and non-porous media [Ph.D. thesis], University of KwaZulu- Natal, Pietermaritzburg, South Africa, 2015.

16. R. M. Kasmani, S. Sivasankaran , M. Bhuvaneswari and Z. Siri "Effect of Chemical Reaction on Convective Heat Transfer of Boundary Layer Flow in Nanofluid over a Wedge with Heat Generation/Absorption and Suction”, Journal of Applied Fluid Mechanics, Vol. 9, No. 1, pp. 379-388, 2016.

17. Alam M. S., Ali M., Alim M. A., Haque Munshi M. J. and Uddin Chowdhury M. Z. "Solution of Falkner- Skan Unsteady MHD Boundary Layer Flow and Heat Transfer past a Moving Porous Wedge in a Nanofluid. Procedia Engineering. 194, 2017, pp. 414-420.

18. Md Shakhaoath K, Ifsana K, Md Haider Ali B: "Non-Newtonian MHD mixed convective power-Law fluid flow over a vertical stretching sheet with thermal radiation, heat generation and chemical reaction effects", Acad. Res. Int., 3(3), 2012, pp.80-92.

19. ImranUllah, IlyasKhan,SharidanShafie " Hydromagnetic Falkner-Skan flow of Casson fluid past a moving wedge with heat transfer" Alexandria Engineering Journal,55(3), 2016, pp. 2139-2148. https://doi.org/10.1016/j.aej.2016.06.023. 
20. Sattar M. A. A "local similarity transformation for the unsteady two-dimensional hydrodynamic boundary layer equations of a flow past a wedge", Int. J. Appl. Math. and Mech., 7(1), 2011, pp.15-28. 2011

21. M.M. Rahman, I.A. Eltaye, "Convective slip flow of rarefied fluids over a wedge with thermal jump and variable transport properties, International Journal of Thermal Sciences, 50, 2011, pp.468-379.

22. Syam Sundar Majety, K. Gangadhar "Viscous Dissipation Effects on Radiative MHD Boundary Layer Flow of Nano fluid Past a Wedge through Porous Medium with Chemical Reaction”, IOSR Journal of Mathematics, 12(5),Ver. IV, 2016, pp.71-81.

23. Rashid Ahmad Waqar Ahmed Khan Effect of Viscous Dissipation and Internal Heat Generation/Absorption on Heat Transfer Flow Over a Moving Wedge With Convective Boundary Condition, Heat Trans Asian Res, 42(7), pp.589-602, 2013; DOI 10.1002/htj.21055.

24. B. Shankar Goud, P. Pramod Kumar, Bala Siddulu Malga "Effect of Heat source on an unsteady MHD free convection flow of Casson fluid past a vertical oscillating plate in porous medium using finite element analysis", Partial Differential Equations in Applied Mathematics, Volume 2, December 2020, 100015.

25. Seddeek M. A., Afify A. A. and Al- Hanaya A. M. "Similarity Solutions for a Steady MHD Falkner-Skan Flow and Heat Transfer over a Wedge Considering the Effects of Variable Viscosity and Thermal Conductivity", An International Journal Applications and Applied Mathematics. 4(2), 2009, pp.301- 313.

26. ATM. M. Rahman, M.S. Alam, M.K. Chowdhury "Thermophoresis particle deposition on unsteady two-dimensional forced convective heat and mass transfer flow along a wedge with variable viscosity and variable Prandtl number", Int. Comm.in Heat and Mass Transfer, 39, 2012, pp. 541-550, doi:10.1016/j.icheatmasstransfer.2012.02.001.

27. Mahanthesh B., Gireesha B.J. and Rama Subba Reddy Gorla. Nonlinear radiative heat transfers in MHD three-dimensional flow of water based nanofluid over a non-linearly stretching sheet with convective boundary condition. Journal of the Nigerian Mathematical Society, 35, pp.178-198, 2016.

28. M.M. Rahman, I.A. Eltayeb, Convective slip flow of rarefied fluids over a wedge with thermal jump and variable transport properties, International Journal of Thermal Sciences,50,2011, pp.468-379.

29. B. Shankar Goud "Heat Generation/Absorption influence on steady stretched permeable surface on MHD flow of a micropolar fluid through a porous medium in the presence of variable suction/injection", Int. Journal of Thermofluids, vol.7-8 (2020) 100044. https://doi.org/10.1016/j.ijft.2020.100044.

30. Srinivas Maripala, N Kishan "chemical reaction effects on MHD nanofluid flow of a convection slip in a saturated porous media over a radiating stretching sheet with heat source/sink", Asian Research Journal of Mathematics 2(1),2017 pp.1-15.

31. N Kishan, C Kalyani, M Chenna Krishna Reddy "MHD Boundary Layer Flow of a Nanofluid over an Exponentially Permeable Stretching Sheet with radiation and heat Source/Sink", Transp Phenom Nano Micro Scales, 4(1), 2016, pp.45-51,2016.

32. C. Srinivas Reddy, N. Kishan, B. Chandra Shekar "MHD Boundary Layer Flow and Heat Transfer of a Nanofluid Over a Shrinking Sheet with Mass Suction and Chemical Reaction", Journal of Nanofluids, 4(4), 2015, pp.518-527. 
33. C. Kalyani, M. Chenna Krishna Reddy, N. Kishan "MHD Mixed Convection Flow Past a Vertical Porous Plate in a Porous Medium with Heat Source/Sink and Soret Effects", American Chemical Science Journal,7(3),2015, pp.150-159.

34. Naikotin Kishan, P Amrutha "Effects of viscous dissipation on MHD flow with heat and mass transfer over a stretching surface with heat source, thermal stratification and chemical reaction", Journal of Naval Architecture and Marine Engineering,7(1),2010, pp.11-18.

35. B. Shankar Goud., Pudhari Srilatha., Dr.K.Ramesh Babu, L.Indira "Finite element approach on MHD flow through porous media past an accelerated vertical plate in a thermally stratified fluid”, Journal of Critical Reviews,7(16),2020,pp.69-74.

36. Hunegnaw Dessie and Naikoti Kishan "MHD effects on heat transfer over stretching sheet embedded in porous medium with variable viscosity, viscous dissipation and heat source/sink", Ain Shams Engineering Journal,5(3), 2014, pp.967-977

37. A Sriramalu, N Kishan, RJ Anand Steady flow and heat transfer of a viscous incompressible fluid flow through porous medium over a stretching sheet, J. Energy Heat Mass Transfer 23,pp.483-495.

38. A. Nageeb, H. Haroun, S. Mondal, and P. Sibanda, "Effects of thermal radiation on mixed convection in a MHD nanofluid flow over a stretching sheet using a spectral relaxation method," Int. Journal of Mathematical, Computational, Physical, Electrical and Computer Engineering, 11(2), 2017, pp.33-42.

39. G. Ashwini and A. T. Eswara, "MHD Falkner-Skan boundary layer flow with internal heat generation or absorption," International Journal of Mathematical and Computational Sciences, 6(5),2012, pp. 556-559.

40. T. Watanabe, "Thermal boundary layer over a wedge with uniform suction and injection in forced flow," Acta Mechanica, 83(3-4), pp. 119-126, 1990.

41. I. Ullah, I. Khan, and S. Shafie, "Hydromagnetic Falkner-Skan flow of Casson fluid past a moving wedge with heat transfer,"Alexandria Engineering Journal, 55(3), 2016, pp. 2139-2148.

42. Wubshet Ibrahim and Ayele Tulu "Magnetohydrodynamic(MHD)Boundary Layer Flow Past a Wedge with Heat Transfer and Viscous Effects of Nanofluid Embedded in Porous Media", Mathematical Problems in Engineering, Volume 2019, Article ID 4507852, 12 pages, https://doi.org/10.1155/2019/4507852. 